\title{
Rudolf von Jhering y el paradigma positivista. \\ Fundamentos ideológicos y filosóficos de su pensamiento jurídico \\ DE LUIS M. LLOREDO ALIX, DYKINSON, MADRID. 2012, 598 Pp.
}

Juan Jesús GARZA ONOFRE

La influencia de Rudolf von Jhering, dentro del ámbito jurídico, es de tales magnitudes que su categorización como un autor clásico, y por ende de lectura obligatoria, resulta inexcusable. Sin embargo, es frecuente que al momento de exponer a dicho pensador - en algún curso de Filosofía jurídica, de Teoría del derecho, o de Introducción al derecho-, antes que explorar la forma en que sus doctrinas influyeron crucialmente sobre el canon iusfilosófico contemporáneo, el elemento central (y muchas veces unívoco) al cual se circunscribe su estudio es la noción de derecho subjetivo, con particular énfasis en su teoría del interés. Así, el análisis que propone la distinción de las distintas facetas en la vida de Jhering, o el estudio de la evolución de sus ideas conforme al contexto en el que este se desenvolvió, por lo general, suele quedar relegado frente a la bibliografía que aborda su obra más bien de forma sucinta y expositiva.

En tal sentido, el influjo que hoy en día tiene Jhering en relación a las nuevas generaciones de estudiantes de derecho, parecería diluirse frente a otros autores ilustres que cuentan con mayor preponderancia desde hace algunos años. Según William Twining, al hacer referencia a la teoría del derecho que se enseña actualmente dentro de la tradición anglo-americana, es posible percibir una corriente dominante de pensamiento ubicada en autores como Dworkin, Hart, Kelsen, el Derecho Natural (por ejemplo, en un pensador como Finnis), Rawls y Raz; y después, aunque ya en un segundo nivel, en juristas como Austin, Bentham, Fuller, Holmes, Llewellyn, MacCormick, Pound, los Critical Legal Studies y quienes conforman la teoría jurídica feminista. ${ }^{2}$ En la tradición continental, no obstante que las encuestas para conocer a los juristas más populares entre estudiantes no son tan comunes, un referente importante - aunque difícilmente representativo- fue realizado en México por Héctor Fix-Fierro y Sergio López-Ayllón: ${ }^{3}$ al preguntar a futuros abogados cuáles habían sido los autores más leídos durante el transcurso de su carrera, destaca la total ausencia de Rudolf von Jhering de los resultados finales (esto a pesar de que la primera traducción al castellano de una de sus principales obras, El fin en el derecho, fue publicada precisamente en este país en 1961). ${ }^{4}$ Bas-

\footnotetext{
${ }^{1}$ Investigador de la Facultad Libre de Derecho de Monterrey.

2 TWINING, William, "Implicaciones de la globalización para el derecho como disciplina". Anales de la Cátedra Francisco Suárez, Departamento de Filosofía del derecho de la Universidad de Granada, Vol. 44, 2010, pp. 349 y 350 .

3 FIX-FIERRO, Héctor y LÓPEZ-AYLLÓN, Sergio, "De las buenas y malas razones para estudiar "leyes". Análisis de una encuesta a estudiantes de derecho en la ciudad de México", en FIX-FIERRO, Héctor (ed.), Del gobierno de los abogados al imperio de las leyes, Estudio sociojurídico sobre educación y profesiones jurídicas en el México contemporáneo, Instituto de Investigaciones Jurídicas, Ciudad de México, 2006, pp. 129-131.

${ }^{4}$ LLOREDO ALIX, Luis M., "La lucha por el derecho como imperativo ético y político. Glosas a Rudolf von Jhering”. Revista Telemática de Filosofía del Derecho, No. 15, 2012, p. 249.
} 
ta solamente con realizar una búsqueda en los catálogos bibliográficos de cualquier acervo jurídico para distinguir los contrastantes resultados entre la abundante cantidad de trabajos dedicados a nombres como Kelsen, Hart, Bobbio, o Dworkin, en comparación con aquellos relativos a Jhering. No por nada, resulta bastante significativo el hecho de que hasta hace solo un par de años, y después de más de un siglo de la muerte de este jurista alemán, se publicara la primera obra monográfica en Hispanoamérica respecto a su pensamiento.

La importancia de dicho trabajo, realizado minuciosamente por Luis Lloredo Alix, no solo radica en su vocación por cubrir una amplia laguna dentro de la vasta bibliografía iusfilosófica en español, sino también, y sobre todo, en revalorizar y reivindicar el papel de Jhering como una figura en la que convergen - unas veces de forma consciente y muchas otras de manera inconsciente- enfoques heterogéneos e ideas revolucionarias que, con el paso de los años, acarrearían consecuencias cruciales para la cultura jurídica.

Si bien es cierto que la conocida premisa enunciada por Italo Calvino respecto a la lectura de autores clásicos - donde afirma que estos han de ser leídos porque sencillamente es mejor que no leerlos -5 resulta suficiente para abocarse a la comprensión de importantes postulado escritos en épocas pasadas, también es innegable que las actuales condiciones de globalización e interdependencia han cambiado radicalmente la manera en que la información es procesada y percibida; y así, cuando la voraz expansión de las telecomunicaciones también ha propulsado un aumento sin igual en la cantidad de producciones científico académicas, parecería que la lectura de los clásicos se ve mermada por su falta de vigencia ante el cambiante panorama que se despliega. Y es que la actualización del contenido de las obras de los autores clásicos resulta una ardua y arriesgada labor que implica no solo indagar sobre nuestro presente, sino también profundizar sobre el pasado, para finalmente concebirlo como un elemento crucial para el entendimiento futuro.

De ahí, precisamente, que la manera en la que es presentado Jhering a través de la obra de Luis Lloredo sea acertada. Porque al tener en consideración las transformaciones que han venido a convertir a la filosofía del derecho en una especie de receptáculo interdisciplinar que aglutina una híbrida gama de asuntos jurídicos, la importancia otorgada a la razón histórica cobra sentido; pues al rescatar tanto aspectos de la figura de Jhering como sucesos ocurridos durante el transcurso del tiempo, el análisis de estos factores se descubre como una de las mejores rutas para explicar el rumbo que ha tomado el pensamiento jurídico contemporáneo.

Vale la pena señalar que el vehemente acercamiento histórico que late en cada una de las páginas del trabajo de Luis Lloredo, encuentra consonancia con la visión y escuela del recién extinto Gregorio Peces-Barba - quien precisamente presidió el tribunal de tesis doctoral, junto a otros juristas ilustres como Elías Díaz o Mario Losano, que inspira la obra que aquí se reseña-, que siempre prestó atención por la historia en el momento de estudiar filosofía del derecho. Tal y como lo afirma el propio autor, "la historia es un arma esencial para el jurista. Si no se quiere caer en un culto reverencial al Derecho vigente, si se quiere salir del círculo vicioso en que nos encierra la legalidad, entonces hay que contemplarla desde la perspectiva diacrónica” (p. 126).

En ese orden de ideas, resalta también que el trabajo aquí presentado, además de estudiar la figura del alemán desde un prisma histórico-jurídico, al utilizar un enfoque ecléctico donde convergen una visión humanística y cultural de la filosofía del derecho, y de la filosofía en

\footnotetext{
5 ITALO CALVINO, Por qué leer los clásicos. Madrid, Siruela, 2009, p. 20.
} 
general, también propugna por romper con una arcaica tradición que se empeña en analizar al derecho como una ciencia aséptica, ajena a cualquier consideración de índole ideológica, evitando de esta forma centrar el estudio exclusivo de Jhering en sus facetas como jurista positivo, romanista o filósofo del derecho. La lectura final que emerge del trabajo de Lloredo, asimismo, puede entenderse como un llamamiento a reflexionar sobre los vínculos entre política y derecho, generalmente desatendidos.

Al comprender el pensamiento de Jhering como el punto de partida de todas esas corrientes que, durante el siglo XX, acentuaron la dimensión social del derecho (como el realismo jurídico en sus variantes estadounidense y escandinava, el uso alternativo del derecho y el pluralismo jurídico, la escuela del derecho libre, o la jurisprudencia de intereses, por mencionar solo algunas), la obra en cuestión no solo lanza una invitación a renovar y revitalizar las teorías jheringianas, sino que también propone, y ejecuta a través de su propio método de investigación, una sagaz crítica contra la propensión al aislamiento de la ciencia jurídica; esto, en sintonía con un cada vez mayor número de pensadores que, como Martha Nussbaum, Michael Ignatieff, o Richard Rorty, se abocan a contemplar las transformaciones del día a día y evitan concebir diferentes disciplinas bajo un enfoque estático y meramente científico.

Al enfatizar el análisis histórico y al utilizar un método de estudio heterogéneo, la propuesta metodológica para abordar a Jhering reúne dos objetivos distintos, que al mismo tiempo resultan complementarios e indivisibles: por un lado intenta entender el pensamiento de un autor clásico para la filosofía del derecho y por el otro devela a este mismo jurista como la vía más adecuada para comprender los diferentes rasgos que constituyen el contenido de ese amplio marco ideológico y epistemológico que se ha denominado polisémicamente como positivismo jurídico.

Así entonces, el trayecto que presenta el profesor Lloredo Alix comienza con un primer capítulo que sorprende a cualquier lector que espera encontrar en su trabajo las típicas caracterizaciones biográficas que sirven para identificar y contextualizar a cualquier personaje sobre el que se quiera profundizar. Pues independientemente de que en el trasfondo de cada una de las páginas de la obra se encuentran latentes las principales ideas de Jhering, lo cierto es que esta inicia con una investigación, que incluso podría leerse de forma independiente, sobre los orígenes del positivismo jurídico. Ahora bien, la lucidez expositiva con la que es abordada esta corriente de pensamiento resulta altamente atractiva no solo para entender los problemas conceptuales en los que tradicionalmente se ha visto inmersa - como su polisemia, su supuesto antagonismo con el iusnaturalismo, o sus múltiples y variados calificativos o "apellidos"-, sino también por su gran contenido didáctico, al trazar una hoja de ruta que identifica al congreso de la ciudad de Bellagio de 1960 (p. 42 y ss.) como el referente a partir del cual se comenzó a debatir profusamente sobre la naturaleza, problemas y soluciones del iuspositivismo. No por nada, a partir de dicho congreso Bobbio, Hart y Ross publican, en 1961, sus respectivas obras Aspetti del positivismo giuridico, The Concept of Law, y El concepto de validez y el conflicto entre el positivismo jurídico y el derecho natural; cuatro años después Uberto Scarpelli haría lo correspondiente con su libro Cos'è il positivismo giuridico. En función de tal acontecimiento, antes que decantarse por una acepción, o acaso repasar ociosamente todas y cada una de las posturas involucradas destacando sus potencialidades y riesgos (como probablemente se encuentran estructuradas muchas otras obras con aspiraciones más bien expositivas), Lloredo decide centrar el desarrollo de este primer apartado en presentar dos métodos de aproximación al iuspositivismo: el conceptual y el histórico. 
Decantándose por el segundo de estos, que a todas luces resulta novedoso por evitar una definición canónica y aludir a "un reflejo cultural de un cambio producido en la esfera política y social” (p. 61), Lloredo sostiene que el origen del iuspositivismo se encuentra íntimamente relacionado con la influencia de la corriente filosófica, conocida como positivismo. En efecto, este es concebido, antes que como una mera teoría científica, como un hecho histórico de largo recorrido que se manifiesta desde el siglo XVIII, se reafirma a lo largo del siglo XIX, y todavía encuentra eco en el siglo XX, y del cual es posible distinguir múltiples manifestaciones en campos tan variados como la literatura, la pintura, las ciencias naturales, la filosofía, o la filosofía del derecho, terminando por revolucionar una gran cantidad de áreas del conocimiento, por comenzar una paulatina transición ideológica y por redefinir los problemas epistemológicos y su manera de abordarlos (p. 119).

Vale decir que una de las principales aportaciones del trabajo es la parte con la que concluye el primer capítulo, relativa a la aplicación de la teoría de los paradigmas científicos de Thomas Kuhn al estudio del positivismo jurídico. Pues después de explicar dicha teoría y analizar su complicada aplicación a las ciencias sociales, Lloredo propone pensar el nacimiento del positivismo jurídico como "una emergencia paradigmática radical..., de gran calado en el mundo de la ciencia del Derecho, que revolucionó la manera de entenderlo y de acercarse a su estudio" (pp. 145 y146). Y es justo en ese momento, cuando Jhering entra en escena de manera explícita en la investigación, al ser evidenciado como epicentro del paradigma iuspositivista, como una pieza clave en la evolución de la dinámica del paradigma, por conjugar tres de los principales vectores sucesivos y complementarios que se desprenden del mismo a lo largo de su trayectoria: el historicismo, el naturalismo y el realismo o pragmatismo (p. 158).

A partir del segundo capítulo, se devela ya por completo la complejidad que arroja el estudio de la figura de Jhering, pues este apartado propiamente vendría a ser aquel que engloba y profundiza en los aspectos ideológicos que contribuyeron en el iuspositivismo del autor. Así, tomando como referencia la propuesta de Scarpelli respecto a la interpretación política del positivismo jurídico, se traza un esbozo en el que el contexto social de la Alemania del XIX, caracterizada por la política bismarckiana, el nacionalismo y el estatalismo, el auge del industrialismo y en general el influjo desaforado del pragmatismo en todos los órdenes de la vida, intervienen directamente en la concepción que el alemán tenía sobre el derecho, orientándolo hacia una visión más "realista, comprometida y activa en la transformación política" (p. 227) de su entorno. Solo entendiendo dicho compromiso progresista de Jhering, respecto a la sociedad y el Estado como instancias supraindividuales con las que el derecho necesariamente debe tener contacto, pero manteniendo una cierta orientación respecto a consideraciones conservadoras y coincidentes con el liberalismo doctrinario, es posible concebir la personalidad y el pensamiento de este jurista como un complejo entramado de ideas jurídico-políticas que entroncan con el iuspositivismo.

Sin embargo, la cuestión respecto a la figura de Jhering no es nada sencilla de resolver. Porque en todo caso, la categorización que suele dividir al pensamiento de este autor en dos etapas bien definidas (la primera empatada con el formalismo y el dogmatismo y la segunda con posiciones antiformalistas), resulta difusa cuando se descubren las variadas interpretaciones que se la han otorgado a su pensamiento, así como también cuando es posible entrever una marcada orientación histórica-crítica desde sus primeras obras hasta la última. De ahí que la aproximación selectiva que se realiza sobre algunos problemas concretos de la 
filosofía de Jhering sea más adecuada para destacar aquellos aspectos que se nutren recíprocamente con el nuevo paradigma intelectual del positivismo jurídico.

A través de la exposición que realiza el autor sobre la crítica al historicismo y al conceptualismo de Jhering, se devela claramente la importancia que implica desmarcarse del "servilismo de las fuentes, ya sean romanas o germanas, y avanzar en una dirección filosóficocomparativa, muy en la línea de lo que enseguida se empezaría a llamar teoría general del Derecho" (p. 283), la relevancia del Estado como factor de desarrollo del derecho y, sobre todo, el despliegue de "las diversas tendencias antiformalistas que salpicaron las primeras décadas del siglo pasado" (p. 307). Así entonces, el reflejo de algunas de las principales aportaciones del jurista alemán al paradigma iuspositivista (como la remisión de la teoría del Derecho al Estado y la sociologización de pensamiento jurídico) dan pie para que Jhering, rechazando una aproximación aséptica al derecho intentando encontrar su fundamento en consideraciones políticas y sociales, circule constructivamente del derecho subjetivo al derecho objetivo, es decir, pase de las preocupaciones por los derechos subjetivos hasta abordar temas como el de los derechos como deberes - y sus interconexiones con la ética, la moral y la política- el Estado y su concepción como un trabajo colectivo, la coacción, la organización social y otros tantos que marcan una clara transición en su pensamiento del derecho privado al derecho público (pp. 332 y ss.).

Esta novedosa propuesta de Jhering respecto a que los derechos deberían dejar de ser algo disponible en manos del beneficiario para ser entendidos como un auténtico deber hacia la sociedad (p.358), aunada a la idea de autolimitación — para contener la relación entre derecho y poder, derecho y violencia-como condición para el reinado del derecho, engendra nuestra concepción moderna de Estado de Derecho. Pero además, "fruto de pensar el Derecho desde la sociedad y no la sociedad desde el Derecho" (p. 386), el pensamiento de Jhering desemboca en una fundamentación de lo que más tarde será entendido como Estado social, el cual se ve emparentado con la emergencia del paradigma iuspositivista, tanto en la dimensión política como científica. Pues, como afirma Lloredo, gracias al surgimiento de la cuestión social "nacieron las primeras orientaciones socio-jurídicas; y también fue así como el Derecho pasó a ser un instrumento destinado a servir de cauce entre Estado y sociedad, como un instrumento que aquél puede emplear para satisfacer las necesidades siempre cambiantes de ésta " (p. 397).

El apartado con el que inicia el tercer y último capítulo — donde el autor expone los diferentes fundamentos filosóficos que explican el iuspositivismo desarrollado por Jheringanaliza las relaciones entre el positivismo y la filosofía, y tiene un valor primordial por vigorizar la concepción que contempla al derecho como un producto cultural, ideológico y político; pues al rastrear los orígenes de la filosofía jurídica y entenderla como consecuencia disciplinar directa del surgimiento del paradigma iuspositivista, y enumerar una serie de factores que han propiciado un distanciamiento entre filosofía y filosofía del derecho, Lloredo enuncia una serie de grandes pensadores que a lo largo del siglo XX han realizado contribuciones teóricas al estudio del derecho y que, sin embargo, suelen ser ignorados por los juristas (pp. 411 y 412): desde Gadamer, pasando por Derrida y Ricœur, hasta Foucault y Cassirer, la lista de filósofos "no juristas" que habitualmente han de permanecer ausentes cuando se estudia filosofía del derecho, resulta una clara manifestación de la propensión al aislamiento disciplinar en la ciencia jurídica.

Así entonces, y en ese mismo sentido, llama la atención la manera en la que se deciden organizar los diversos influjos en el pensamiento del jurista alemán: no solo se estudian las 
proyecciones del historicismo - haciendo especial énfasis en las figuras de Montesquieu y Hegel-(pp. 426 y ss.), del utilitarismo - en su vertiente anglosajona y en el eudemonismo germano- (pp. 482 y ss), y las ciencias sociales y naturales (pp. 520 y ss.) en el pensamiento de Jhering, sino que también se investiga la relevancia de cada una de estas corrientes de pensamiento en la transformación de la cultura, la ciencia y su relación con la filosofía del derecho. Estos tres grandes temas sirven para entender su obra como un reflejo de "una época de cambio, de encrucijada y apertura de nuevos caminos. Por eso se palpan resabios de las etapas anteriores y también, al mismo tiempo, se lanzan cabos aventurados hacia el futuro" (pp. 425 y 426).

Aunque resulte difícil condensar las quinientas cuarenta y seis páginas de contenido de la obra de Lloredo, ya sea por las profundas digresiones filosóficas planteadas a lo largo de la misma o por las múltiples asociaciones que reflejan la magnitud del paradigma positivista en diferentes áreas del conocimiento, lo cierto es que la arriesgada apuesta por comprender el denso y complejo pensamiento de Jhering a la luz del iuspositivismo, no solo es adecuada porque presenta una lectura en clave crítica del estado actual de la filosofía del derecho, sino también por clarificar las principales aportaciones del jurista alemán a la teoría jurídica, y a la cultura jurídica contemporánea en general. En ese sentido, al finalizar la lectura de la obra en cuestión, la sensación de estar en deuda permanente con Rudolf von Jhering resulta inevitable. No por casualidad, Manuel Atienza, en el último capítulo de su Curso de argumentación jurídica, donde realiza una especie de diálogo ficticio para dejar constancia de que la teoría del derecho no puede reducirse a las teorías de argumentación jurídica que en años recientes han caracterizado a la filosofía del derecho, después de enaltecer distintos pasajes de la obra de Jhering y manifestar su entusiasmo por el mismo, menciona que, hoy en día, tendríamos que sentirnos más herederos de este jurista que de Kelsen. ${ }^{6}$

Y es que, bajo la guía de Lloredo, se descubre que al examinar detenidamente las derivas filosóficas e ideológicas en el pensamiento jurídico de Jhering, se ordenan esa multitud de ideas, tan inconexas como interdisciplinarias, que se encuentran en la obra del alemán, las cuales constituyen las bases de muchas de las tendencias iusfilosóficas contemporáneas y, sobre todo, del entendimiento del derecho como fenómeno social; un entendimiento que, antes que centrarse en su propia forma o estructura - como posteriormente propondría Kelsen-, debe prestar minuciosa atención a su finalidad, a su vinculación con el poder y las relaciones sociales, para intentar resolver los graves problemas que, a lo largo del tiempo, han aquejado a nuestro entorno.

Al estudiar a Jhering se reivindica su papel frente a las nuevas generaciones de estudiantes de derecho, en cuyas manos estará el devenir de la ciencia jurídica y la construcción de un mejor escenario en armonía con los contenidos de aquella y las siempre inciertas necesidades y dificultades de la sociedad. No cabe duda de que leer hoy a Jhering, sencillamente resulta mejor que no leerlo. La lectura de este autor clásico, a la par de una visión como la presentada por Lloredo, nos coloca en una posición privilegiada para comprender un sinfín de cuestiones sobre el derecho y sus configuraciones actuales: porque ahí justamente radica una razón más para reforzar la respuesta a la pregunta de Calvino sobre la lectura de autores clásicos, porque al realizar dicho acto estaremos analizando críticamente las complejas circunstancias que se nos despliegan para advertir las eventuales problemáticas del futuro; pues como bien dice la cita de Claudio Magris que abre el trabajo de Lloredo: "La vida, decía

${ }^{6}$ ATIENZA, Manuel, Curso de argumentación jurídica, Trotta, Madrid, 2013, p. 809. 
Kierkegaard, sólo puede ser entendida mirando hacia atrás, aunque deba ser vivida mirando hacia adelante - o sea, hacia algo que no existe". 